\title{
THE EFFECT OF THE EIDAS REGULATION ON THE MODEL OF HUNGARIAN PUBLIC ADMINISTRATION
}

\author{
Gábor Klimkó1 ${ }^{1}$ Péter József Kiss and József Károly Kiss ${ }^{2}$
}

\begin{abstract}
Regulation (EU) $N^{\circ} 910 / 2014$ on electronic identification and trust services for electronic transactions in the internal market, adopted on 23 July 2014 (hereinafter the eIDAS Regulation) is a significant step towards providing such a predictable regulatory environment that enables secure and seamless electronic interactions between businesses, citizens and public authorities of the members of the European Union. The Regulation ensures that people and businesses are allowed to use their own national electronic identification schemes (eIDs) to access public services in other EU countries where eIDs are available, moreover, it introduces the concept of trust services and prepares for the harmonization of further areas.
\end{abstract}

Unfortunately, the eIDAS Regulation together with the Commission Implementing Regulation 2015/1501 is not in perfect harmony with the established and emerging models of operations in public administration in Hungary and consequently a common foundation for secure electronic interaction could be provided only with strong limitations.

To avoid this undesirable situation, the paper proposes the introduction of two registration procedures (built on the basis of the services in the scope of the Regulation) that would complement the missing data items in a transparent manner. This extension would result in the provision of all registered electronic services of the EU countries for all EU citizens.

\section{Introduction}

The growing internet penetration created a demand for conducting business by on-line means. The private sector responded by offering proper electronic services, and consequently the need for servicing the clients on electronic channels appeared in public administration, too. In order to provide an electronic service to a client there is a need for a proper way of identifying and authenticating the requesting entity (note that in public administration there are different requirements on the electronic identification as opposed to the private sector). The different identification schemes built by the public administrations of separate European countries did not make it possible to offer cross-border electronic identification services. There were studies and pilots to tackle the problem [1], [2], [3]. The final legal solution to deal with the obstacles of crossborder electronic identification services is the Regulation (EU) N910/2014 on electronic identification and trust services for electronic transactions in the internal market, adopted on 23 July 2014 (hereinafter the eIDAS Regulation) [4]. The specific measures described in the text of the Regulation, however, are not directly applicable in the model of operations in public administration of Hungary.

\footnotetext{
${ }^{1}$ Budapest Corvinus University, 1093 Budapest, Fővám tér 13, gabor.klimko@uni-corvinus.hu

${ }^{2}$ MTA Information Technology Foundation, 1525 Budapest Pf. 49., Hungary, mtaita@t-online.hu
} 


\subsection{Identification of natural persons in Hungary}

In the Hungarian public administration natural persons are identified traditionally by their four "natural" identifying pieces of data, as

- $\quad$ the name of the person;

- the place of birth of the person;

- the date of birth of the person and

- $\quad$ the person's mother's name. [5]

In the case of married women, changing a registered name was usual and accepted therefore a fifth piece of data, the "maiden name" is also used.

Identification in person happens on the basis of a photo ID card (pass) that links the "natural" identifying data with the photo. As computerized registers appeared there was need for using unique identifiers (keys) and for that purpose sectoral identification numbers were introduced (tax identification number, social security number). The official documents that prove the sectoral identification numbers do not have any photo but the natural identifying pieces of data [6]. There were two steps during the in person identification process before processing a sectoral case, as

1. The client was compared to his/her photo on the presented ID card. Having ascertained that the same person has shown the ID card the corresponding natural identifying pieces of data were read from it.

2. The natural identifying pieces of data were compared with the presented sectoral official document. Having stated that they are the same, the sectoral identification number was read.

Note that the set of natural identifying pieces of data is not perfect in the sense that it is not unique; there are a few different existing persons whose aforementioned identifying pieces of data are the same. The Hungarian public administration authorities could live with that shortcoming.

The increased usage of computerized systems naturally led to the idea of using a unified sector independent personal identifier, the personal identification number. This identification number is used in the so-called Register of Citizens that was set up because of Act LXVI of 1992 on Keeping Records on the Personal Data and Address of Citizens [7]. The universal usage of the personal identification number, however, was legally challenged on the basis of constitutional personal data protection principles. The Hungarian Court of Constitution accepted the complaint and in its decision 15/1991. (IV. 13.) declared the usage of a universal personal identification number to be against the Constitution [8].

After the announcement of this decision of the Court of Constitution, only sectoral identification numbers were used while conducting the sectoral cases, otherwise case processing was based on the natural identifying pieces of data [9]. As the "name of the person" cannot be considered to be a permanent data item, it was replaced with "the birth name of the person". At the end of this process, all the registers that support the operations of the Hungarian public administration provided for natural persons are based on the natural identifying pieces of data. Provision of the natural 
identifying pieces of data is compulsory in all administrational processes for natural persons. Registers used in the processes exchange data by using natural identifying pieces of data. The Register of Citizens contains the authentic (trustworthy) personal data, including the natural identifying pieces of data, of persons living in Hungary [7].

In Hungary when a person uses an (on-line) electronic public administration service, he should identify himself by certain means (via the so-called Client Gate [10], [11], or by using an electronic personal ID card). Having been identified the sectoral identification number of the person can be determined on the basis of the so-called "Disposition Register" [12]. The raison d'etre of the Disposition Register was the need for such a linking method that is legally acceptable and does not offend the decision of the Court of Constitution. For that purpose, a method based on usage of Encrypted Anonymous Linking Codes (EALCs) was developed, and EALCs of natural persons are stored in the Disposition Register ${ }^{3}$. Storing a new record related to a person into the Disposition Register is done also on the basis of the natural identifying pieces of data. The legal background of this method is laid down in Act XX of 1996 on the Identification Methods Which Replace the Personal Identification Number and on the Usage of Sectoral Identification Numbers [9]. The method is described in detail in [13].

There are, however, such natural persons whose data is not stored in the Register of Citizens but they are entitled to use electronic public administration services by the law. The term "Register of Citizens" refers to two registers, one for Hungarian citizens and another one for such persons that do not possess Hungarian nationality but live permanently in Hungary (they should have a residency permit). Note that the nationality of a client can be determined from these registers.

The need for providing electronic public administration services for foreign individuals, however, was also raised and a dedicated register was set up that contains the data of those foreign clients who want to use electronic Hungarian public administration services. Clients that register voluntarily into this dedicated register are allowed to claim a Client Gate. Note here that owners of the Client Gates also obtain a means of secure electronic delivery of official electronic documents [12].

\subsection{Identification of legal persons in Hungary}

There are a number of types of legal persons in Hungary. Companies are all legal persons by the Act of V. of 2013 on the Civil Code. Non-governmental organizations can (but are not obliged to) be a legal person, too. There are separate registers for different types of organizations. Affairs of the legal persons are managed and conducted by such natural persons who are entitled (are granted the necessary permission) to do so. Identification of legal persons is therefore referred back to the identification of natural persons.

In order to provide electronic public services for legal persons currently a Client Gate technology (that is bound to a natural person) is used. A new service called "Business Gate" is being offered, however, it can be used only by the authorized (assigned) natural persons, therefore the identification process is based on the identification of natural persons [14].

\footnotetext{
3 The homepage of this service can be found at https://rendelkezes.kekkh.gov.hu/rny-public/\#en_nav (accessed: 7 March, 2018)
} 


\section{The rules of the EIDAS regulation and the Hungarian practice}

The EIDAS Regulation enables secure and seamless electronic interactions between businesses, citizens and public authorities of the members of the European Union. The Regulation ensures that people and businesses are allowed to use their own national electronic identification schemes (eIDs) to access public services in other EU countries where eIDs are available, moreover, it introduces the concept of trust services and prepares for the harmonization of further areas.

However, there are problems with the implementation of the prescripts of the EIDAS Regulation into the Hungarian practice in three areas. We shall scrutinize these areas one by one.

\subsection{Identification of a natural person}

The Annex of the Commission Implementing Regulation (EU) 2015/1501 of 8 September 2015 on the interoperability framework pursuant to Article 12(8) of the eIDAS Regulation prescribes four mandatory and four additional data elements to be transmitted to the affected electronic services. The minimum data set (the mandatory data elements) for a natural person are

(a) current family name(s);

(b) current first name(s);

(c) date of birth and

(d) a unique identifier constructed by the sending Member State in accordance with the technical specifications for the purposes of cross-border identification and which is as persistent as possible in time [15].

In the Hungarian practice of operating registers (d) cannot be straight handled as none of the registers is ready to store a unique identifier due to the fact that it is legally forbidden to use such a (unique) identifier for Hungarian citizens. Data element (a), that is, current family name is not a piece of permanent data as married women's name often change in a number of countries. As a consequence the minimum data set is not appropriate for processing a public administration case in Hungary.

The additional (optional) attributes for a natural person in the eIDAS Implementing Regulation are

(a) first name(s) and family name(s) at birth;

(b) place of birth;

(c) current address and

(d) gender [15].

The (a) "first name(s) and family name(s) at birth" is enough for a more specific identification. The (c) "current address", however, is not permanent data therefore it is not appropriate for identification. In order to map to Hungarian practice the "person's mother's name" data element is missing. As this data element is compulsory in Hungary, its absence would lead to the modification 
of a number of basic Hungarian registers and the related processes. The cost consequences and time requirements of such a change would be highly questionable therefore another solution is needed.

The nationality as a data element is not in the minimum data set for natural persons. There might persons who have eIDAS ID but have no nationality of an EU-member state. For example, Estonia introduced the concept of "virtual nationality", and it is also the case in Hungarian practice that persons with foreign nationality are given the right to use electronic public services. This is problematic from the point of authentication for a cross-border service even when identification is successful. There can be such rights that only citizens of EU countries can be granted and persons of other nationalities are not allowed to have (even when they have a residential permit). In such cases, cross-border services cannot be offered to the identified person. Inclusion of nationality in the minimum data set does not solve finally this problem as nationality is not permanent, but it would improve the current situation.

A particular case in eIDAS identification processes is when the data of a natural person, acting on behalf of another natural person, is to be transmitted [16]. As this data is allowed to be sent without a request and there is no additional attribute with it, it could result in a permanent and comprehensive authorization for all kinds of cases. This approach, however, is not the best solution. In the Hungarian system, one rationale behind the introduction of the Disposition Register was to avoid giving such unconditional authorization.

\subsection{Identification of a legal person}

The Annex of the eIDAS Implementing Regulation prescribes the following minimal data set for identification of legal persons, too. The mandatory attributes are

(a) current legal name;

(b) a unique identifier constructed by the sending Member State in accordance with the technical specifications for the purposes of cross-border identification and which is as persistent as possible in time.

The additional attribute are

(a) current address;

(b) VAT registration number;

(c) tax reference number;

(d) the identifier related to Article 3(1) of Directive 2009/101/EC of the European Parliament and of the Council (1);

(e) Legal Entity Identifier (LEI) referred to in Commission Implementing Regulation (EU) No $1247 / 2012(2)$

(f) Economic Operator Registration and Identification (EORI) referred to in Commission Implementing Regulation (EU) No 1352/2013 (3) and 
(g) excise number provided in Article 2(12) of Council Regulation (EC) No 389/2012

There is a principle problem with the personification of a legal person. An organization, as an abstract entity, cannot participate in an interactive contact. Rather, a natural person will act on behalf of that organization. It is possible that in the future a robot (chatbot) will act on behalf of the organization but it is meaningless to prepare for this at G2B liaisons. For such purposes a dedicated machine-to-machine connection seems to be appropriate. An example for such a machine-tomachine connection in the Hungarian practice is when cash registers "report" to the tax office, and this communication, of course, differs from human conversation.

According to the EIDAS Implementing Regulation requirement on the minimal data set for legal persons only one unique identifier is to be sent to the affected parties, therefore it is also not a solution if the (representative of the) legal person asks for more than one means for the same identifier. In the Hungarian practice this approach is avoided. If a person acts on behalf of a legal person, the usage of a single identifier (e. g a smartcard) by several persons raises security as well accountability problems; think of the case when a confidential code or the smartcard is passed from one to another. In the Hungarian taxation system, for example, the usage of the Client Gate for electronic VAT reporting is possible for micro enterprises [17]. That led to a situation when the Client Gate of a self-employed entrepreneur was used on behalf of the enterprise by their bookkeeper even though the Client Gate was designed to be a personal tool. The use of a Client Gate by two persons made impossible to determine who was accountable for what in a certain situations.

Any identification method that can be used by more than one individual might cause problematic situations not only for the legal person but for the public administration, too. Let us consider the case of a criminal abuse with legal consequences (e.g. giving an inciting statement), here the electronic identification does not guarantee that the responsible person can be unequivocally identified. However, there is a basic assumption in the Hungarian practice that there is a natural person who wants to act on behalf of the legal person. That is the reason why identification of that person is strictly required and there are separate dispositions that describe the authorizations for different procedures. In summary, organizational level authentication as such is not handled properly.

The eIDAS Implementing Regulation makes it possible in Article 11 (2) the combined verification of data related to a natural person and to a respective legal person [15]. This procedure can be linked (mapped) to the Hungarian practice as it identifies the acting natural person as well as it identifies the represented legal person, too.

Still, there are concerns of this usage. The procedural rights related to a legal person are usually not based on a generic authorization. For example, a bookkeeper might be allowed to represent a legal person only in relation to the Tax Office but in a litigation procedure only the legal advisor of the legal person is entitled to make a statement. Furthermore, it is often the case with transactions of significant value that more than one person jointly are entitled to make a (legal) statement. However, the approach used in the eIDAS Implementing Regulation relies on the concept of having one person's exclusive, unlimited procedural right [15]. Such an unlimited procedural right is usually granted only for the chief executive officer of a legal person.

In the Hungarian practice acting authorizations are recorded in separate registers, for example for tax related procedures authorization data is stored at the Tax Office [18]. For general public 
administration matters these authorizations are recorded in the Disposition Register. The administration process is based on the identification of the natural person and on checking his acting authorizations in a separate register. On this basis the combined identification prescribed by the eIDAS Implementation Regulation can be mapped to the Hungarian model of public administration. Unfortunately, this mapping bears significant risks for the legal persons who utilize it as it has been described in the previous paragraph.

\subsection{The problem of maintaining contacts}

The Regulation ensures that people and businesses are allowed to use their own eIDs to access public services in other EU countries, however, it does not deal with the mutual recognition of the trust services and their possible collaboration. This shortage results in a problem during maintaining relationships with a client.

In the practice of the Hungarian public administration the dominant sequence is the submission of application followed by an administrative decision, where the possibility of a legal remedy for the client is granted by the law. The administrative decision is made by a civil servant who is not always available at the moment of the submission of the application. It is necessary therefore to provide an authentic proof of the time of delivery of the decision to the client, as usually this is the starting time of the deadline of a legal remedy. Had the client refused the receipt of the decision then this will be the starting time of the deadline when the decision becomes final and binding. In order to conduct effective administration it is a basic precondition that the official availability of the client is guaranteed.

The eIDAS Regulation Section 7 introduces the concept of "electronic registered delivery service", and its qualified version ("qualified electronic registered delivery service"). In Article 44 the eIDAS Regulation also states that "...the Commission may, by means of implementing acts, establish reference numbers of standards for processes for sending and receiving data" [4]. However, the obligation of mutual acceptance among the qualified electronic registered delivery services is not stated. In the world of the paper-based, traditional mail there are international agreements that describes the conditions of the reception and shipping [19]. These issues are not currently addressed by the legal environment for the electronic delivery services.

At this point the interpretation of maintaining (electronic) contacts should be clarified. The eIDAS Implementing Regulation mentions the "current address" both for the natural and for the legal persons as part of the minimal data set [15]. The Hungarian practice, however, requires exclusive electronic communication in some areas (for example registering a new company [20], certain tax related administrative activities [17] etc.) for decreasing the cost incurred by the state. In those areas the paper based communication is not possible at all. The duty required for the administrative action harmonizes to the obligation of electronic communication; in a lot of cases the service is free for the client. In these areas, with these conditions the re-introduction of paper-based communication would lead to a disproportionate burden for the Hungarian public administration. The requirement of paying duty for the paper-based version of such services would lead to discrimination for nonHungarian EU citizens, though it would be based on real excess costs.

In summary, maintaining asymmetric contacts where a foreign citizen submits electronically an application but the Hungarian authorities would be able to respond only in a paper-based manner, is not an acceptable solution. It is necessary to provide a verified delivery for those who identified themselves by an eIDAS-conform identification scheme, too. The ultimate solution would be to 
connect the national qualified electronic registered delivery services, but for the time being a temporary solution is to be set up in order to enable the conducting of effective on-line administrative procedures from abroad in Hungary.

\section{Proposals for bridging the gap between the EIDAS Regulation and the Hungarian practice}

\subsection{The case of natural persons}

The need for the provision of electronic services already appeared in the Hungarian public administration, in fact it was the reason to set up a separate register for those foreigners who are going to use such services. Limitations that stem from the eIDAS Regulation can be lifted by the development of this register.

We identified three obstacles in the minimal data set for natural persons, as

1) the lack of the name of the mother of the client;

2) the lack of nationality and

3) the lack of the electronic delivery address.

These obstacles could be remedied by using a registration process. Requiring a registration process for the first time when somebody wants to use a Hungarian electronic service by eIDAS identification would not be a substantive burden for the foreign clients. This is a quite a common procedure in webshops or a portal before using the services offered. The current practice is that one could register only by personal appearance into the register of those foreigners who are going to use Hungarian electronic services. It is justified to revise the requirement of personal appearance and let the clients register electronically by using an eIDAS-conform eID scheme, requiring the aforementioned three data elements. The missing data is sent by the identified client who is also allowed to upload scanned documents to support his statements. The upload of supporting documents, however, is not a mandatory condition for the registration as the possibility of submission of false data is low because a client can be identified by his eIDAS-conform eID-service provider. For some types of cases (e.g. land property acquisition) the civil servant could check the uploaded supporting documents and would be able to make a decision. This extension has significance, for example in handling citizenship-related matters as it provides filtering - it is easier to state a false statement than to create a picture of a false document.

Recording of a client into the above mentioned register makes it possible for him to ask for a Hungarian electronic delivery address (and service). As a result, this client has the same possibilities to conduct electronic business with the Hungarian authorities as clients with Hungarian nationality.

\subsection{The case of legal persons}

A basic obstacle in the mandatory minimal data set for legal persons is that no acting person is referred. The case of the legal persons (organizations) is more complex as currently there is no single Hungarian register for them. The data that describes procedural authorization is stored in a separate register (in the Disposition Register), and they separately register their electronic contact 
addresses. These registers are built upon other base registers (the commercial register, register of non-governmental organizations), and, unfortunately, certain types of organizations cannot be properly described. On that basis it seems justified to set up a new dedicated register for those (nonHungarian) organizations that intend to use a Hungarian electronic service by eIDAS identification and are not already registered in a related Hungarian register.

There would be two ways to be recorded into this new register of organizations, as

1) the organization using an eIDAS-conform eID scheme could state who is the authorized person is to conduct business on behalf of that organization. This person could be identified by an eIDAS-conform eID or by a Hungarian identifier; or

2) in case of combined eIDAS identification, where an organization (legal person) and a (natural) person is identified at the same time, the necessary data will be recorded immediately.

The person that was registered with the right of acting on behalf of the registered organization (legal person) could ask for a (qualified) electronic delivery service (address) in a separate step. Having done that, the handling of all legal persons would be routed back to the current Hungarian practice. The person with the acting right whose name is recorded into the new register could give procedural authorization for other persons by entering into the Disposition Register, but now in a selective manner (either related to specific authorities or a specific types of case). That is, that person could take advantage of all opportunities that are guaranteed for Hungarian persons and legal persons.

\section{Summary}

The rules laid down in the eIDAS Regulation indirectly suppose that there is a unique identifier (both for natural and legal persons) in the different EU countries that is allowed to be used universally for the provision of services. In Hungary, however, the universal usage of a personal identifier is forbidden by the decision of the Court of Constitution. This obstacle can be handled by a registration mechanism on the national level that would be a minimal excess burden but makes effective cross-border usage of electronic services possible.

The Regulation also ignores the requirement of verified electronic accessibility of the client during the administration process (this is the problem of electronic delivery). The ultimate solution for this obstacle is the collaboration of the national qualified electronic registered delivery services. Until this collaboration is implemented, certain national registered delivery services could be extended to maintain contacts with foreign clients.

\section{Acknowledgement}

This work was created in commission of the National University of Public Service under the priority project KÖFOP-2.1.2-VEKOP-15-2016- 00001 titled „Public Service Development Establishing Good Governance" in (the) Ludovika Workshop/Ludovika Research Group/Győző Concha Doctoral Program/Miklós Zrínyi Habilitation Program/István Egyed Postdoctoral Program/Lajos Lörincz Professor Program. 


\section{References}

[1] LEITOLD, H. (2010) Challenges of eID interoperability: the STORK project. In IFIP PrimeLife International Summer School on Privacy and Identity Management for Life (pp. 144-150). Springer, Berlin, Heidelberg.

[2] MOLNÁR, B., KÖ, A., KISS, J. (2006). Identity-Background Checking a Solution, which Meets the Requirements of Privacy and Personal Data Protection at Identity Management Domain, SEFBIS JOURNAL 1:(1) pp. 22-32.

[3] TAUBER, A, et al. (2010) Towards interoperability: an architecture for pan-European eIDbased authentication services. International Conference on Electronic Government and the Information Systems Perspective. Springer, Berlin, Heidelberg.

[4] Regulation (EU) N910/2014 on electronic identification and trust services for electronic transactions in the internal market, adopted on 23 July 2014. Available at http://eur-lex.europa.eu/legal-content/EN/TXT/PDF/?uri=CELEX:32014R0910\&from=EN (accessed: 12 December, 2017)

[5] Act CXL of 2004 on the General Rules of Administrative Proceedings and Services, Available in Hungarian at http://njt.hu/cgi_bin/njt_doc.cgi?docid=85989.328049 (accessed: 12 December, 2017)

[6] PÉTERFALVI, N. et al. Fundamentals of electronic administration, regulated electronic administration services, IT security. Government Window Administrator Postgraduate Education, 5. module. Available in Hungarian at http://kab2.uninke.hu/downloads/KAB2_5Modul_1.\%20nap_anyaga_elmeleti_resz.pdf (accessed: 1 December, 2017)

[7] Act LXVI of 1992 on Keeping Records on the Personal Data and Address of Citizens. Available in Hungarian at http://www.valasztas.hu/parval2006/en/02/1992_66tv.html (accessed: 12 December, 2017)

[8] HUNGARIAN COURT OF CONSTITUTION, Decision 15/1991. (IV. 13.) 983/B/1990. Hungarian Official Gazette, 1991, No. 39., pp.40.

[9] Act XX of 1996 on the Identification Methods Which Replace the Personal Identification Number and on the Usage of Sectoral Identification Numbers. Available in Hungarian at http://njt.hu/cgi_bin/njt_doc.cgi?docid=26379.344890 (accessed: 12 December, 2017)

[10] EUROPEAN COMMISSION, eGovernment in Hungary, Edition 16.0., 2014. Available at https://joinup.ec.europa.eu/document/egovernment-hungary-april-2014-v160 (accessed: 12 December, 2017)

[11] OECD , OECD e-Government Studies: Hungary 2007, OECD Publishing, Paris (2007). DOI: http://dx.doi.org/10.1787/9789264030527-en 
[12] Act CCXXII of 2015 on the General Rules for Electronic Administration and Trust Services, Available in Hungarian at http://njt.hu/cgi_bin/njt_doc.cgi?docid=193173.338642 (accessed: 12 December, 2017)

[13] KISS, J. K., KISS, P. J., \& KLIMKÓ, G. (2015) A Model of Secure Interconnection of Registers Containing Personal Data. In Proceedings of the $15^{\text {th }}$ European Conference on eGovernment, ECEG 2015 University of Portsmouth (p. 149).

[14] Government Decree 451/2016. (XII. 19.) on the on the Detailed Rules of Electronic Administrative Services, Available in Hungarian at http://njt.hu/cgi_bin/njt_doc.cgi? docid=199341.346971 (accessed: 12 December, 2017)

[15] COMMISSION IMPLEMENTING REGULATION (EU) 2015/1501 of 8 September 2015 on the interoperability framework pursuant to Article 12(8) of Regulation (EU) No 910/2014 of the European Parliament and of the Council on electronic identification and trust services for electronic transactions in the internal market, Available at http://eur-lex.europa.eu/legalcontent/EN/TXT/PDF/?uri=CELEX:32015R1501\&from=EN (accessed: 12 December, 2017)

[16] eIDAS Technical Subgroup, eIDAS SAML Attribute Profile V1.1-2, 2016. Available at: https://ec.europa.eu/cefdigital/wiki/display/CEFDIGITAL/eIDAS+Profile (accessed: 12 December, 2017)

[17] Act XCII of 2003 on the Rules of Taxation, Available in Hungarian at http://njt.hu/cgi_bin/njt_doc.cgi?docid=75807.346570 (accessed: 12 December, 2017)

[18] Ministerial Decree NGM 47/2013. (XI. 7.) on the Rules Governing the Electronic Administration of Tax Matters before the State Tax Administration and the Amendment of Other Ministerial Decrees on Taxation. Available in Hungarian at: http://njt.hu/cgi_bin/njt_doc.cgi?docid=164674.287731 (accessed: 12 December, 2017)

[19] Hungarian Post, General Terms and Conditions for Universal Postal Services. Available at: https://www.posta.hu/static/internet/download/PASZF_ASZF01_ASZF_angolul_20131001.p df (accessed: 12 December, 2017)

[20] Act V of 2006 on Public Company Information, Company Registration and Winding-Up Proceedings, Available in Hungarian at: http://njt.hu/cgi_bin/njt_doc.cgi?docid= 101684.339333 (accessed: 12 December, 2017) 